\title{
España y Argentina durante la Segunda Guerra Mundial
}

\author{
MÓNICA QUIJADA
}

Es evidente que las relaciones con la Argentina no fueron las más decisivas mantenidas por España durante la segunda guerra mundial; lo mismo puede afirmarse desde la perspectiva de ese pais hispanoamericano. Más obvio aún resulta el hecho de que ni el desarrollo, ni el resultado de la contienda dependieron en ningún momento de los contactos hispano-argentinos, ni tan siquiera fueron influidos por éstos. No obstante, durante el período de la guerra y muy particularmente desde 1942, esas relaciones fueron objeto de una atención inusitada en los medios internacionales, al extremo de llegar a ser bautizadas con un nombre específico, que era en sí mismo portador de una imagen político-ideológica escasamente halagüeña: el Eje Madrid-Buenos Aires. Más aún: esa misma imagen se proyectó sobre las relaciones hispano-argentinas en los años de la posguerra y en ciertos medios académicos se le siguió asignando valor explicativo hasta fechas relativamente recientes.

El Eje Madrid-Buenos Aires consistía en la percepción internacional de la existencia de una compleja trama, cuyos objetivos últimos excedian los intereses de los dos paises implicados. En otras palabras, desde dicha percepción la relación de ambos países se estructuraba a partir de un triángulo, dos de cuyos lados - Madrid/Buenos Aires- actuaban en la superficie y servian de tapadera al tercero, que constituia el verdadero poder desde la sombra y que no era otro que la Alemania de Hitler. Todas y cada una de las acciones constitutivas de las relaciones hispano-argentinas fueron interpretadas a la luz de esa percepción específica.

Una circunstancia fundamental subyace a dicha interpretación, como punto de partida y condición necesaria, aunque de ninguna manera suficiente. Esa circunstancia es el hecho de haberse producido un acercamiento indudable entre los dos paises durante el quinquenio de la guerra, que se tradujo en una revitalización de los lazos económicos, de los 
contactos políticos y de las apelaciones mutuas en los discursos públicos. Acercamiento de una envergadura inédita hasta entonces y que no volvería a repetirse más tarde, con la única excepción de los tres primeros años de la posguerra, que en parte fueron una continuidad con respecto al quinquenio precedente.

Para poder penetrar en el contenido de ese acercamiento, es imprescindible tener en cuenta el momento específico en que se produjo y sus implicaciones. Es decir, el hecho mismo de la guerra mundial, entendida aqui como una situación de anormalidad que afectó al conjunto de las interacciones entre los países del área occidental $y$, como correlato, a las circunstancias internas de cada pais. A esa situación de anormalidad global se sumó una circunstancia especifica: la reivindicación, tanto por parte de Argentina como de España, de una posición de neutralidad frente a la contienda. No me interesa aquí hacer una valoración de la política española, ni detenerme en su evolución desde una postura de no beligerancia pro-Eje a otra formalmente menos comprometida (sobre lo que otros colegas, más entendidos que yo en la materia, hablarán en el transcurso de estas sesiones). Tampoco es mi intención volver a extenderme sobre las circunstancias que alimentaron la neutralidad argentina, que han sido discutidas y confirmadas por un nutrido número de investigadores en los últimos veinte años, incluyéndome a mí misma '. Me interesa en cambio, y es pertinente al tema que voy a desarrollar, definir inicialmente una conceptualización de la neutralidad que se aparta de su sentido genérico de equidistancia o autoexclusión de un conflicto ajeno, optando por una perspectiva diferente, que aborda la neutralidad como una toma de posición no legitimada por la polarización inherente a dicho conflicto.

Desde este enfoque, la neutralidad como postura política deja en segundo plano la valoración de sus contenidos desde los propios actores de la misma -España y Argentina-, y la discusión toma como eje la perspectiva de los observadores externos -en este caso, el sector del ámbito internacional identificado con la causa aliada-. Es esta cualidad de «ilegitimación externa", y no la neutralidad misma, por muchos adjetivos que se le añadan, lo que puede contribuir a definir los alcances del particular

Véase, entre otros, G. Di Telia y D.C. Watt: Argentina between the Great Powers, 19391946, Oxford, 1989; C. Escudé: 1942-1949. Gran Bretaña. Estados Unidos y la Declinación Argentina, Buenos Aires, 1983; R.A. Humphreys: Latin America and the Second World War, 19391945, London, 1981; R. Newton: The Nazi Menace in Argentina, Stanford, 1992; M. Quijada: Relaciones hispano-argentinas 1936-1948. Coyunturas de Crisis, Madrid, 1989; M. Rapoport: 1939-1945. Gran Bretaña, Estados Unidos y las clases dirigentes argentinas, Buenos Aires, 1980. 
acercamiento hispano-argentino que se produjo durante la contienda internacional. En este sentido, es conveniente recordar que neutrales ante la contienda hubo más de dos, pero que no todos recibieron el mismo tratamiento.

La segunda guerra mundial -entendida como una situación de anormalidad-, y la neutralidad - entendida como una toma de posición no legitimada por la polarización inherente a ella - contribuyeron a desestructurar el status quo de cada uno de los dos paises protagonistas de este trabajo y, con ello, abrieron camino a procesos respectivos de reacomodamiento que en su proyección internacional entrañaban una búsqueda de complementariedad.

Es a partir de estos ejes de análisis que propongo hacer una revisión de los contactos hispano-argentinos durante la segunda guerra mundial. Comenzaré por presentar los elementos constitutivos de las relaciones bilaterales, consideradas éstas como una expresión más -aunque privilegiada- entre la panoplia de contactos que conformaron las relaciones externas de cada uno de los dos países en ese periodo particularmente delicado que fue la guerra mundial. Ello deberá permitirnos redefinir los alcances de esa atracción mutua que fue percibida como un Eje MadridBuenos Aires, con Berlín como telón de fondo.

\section{LAS RELACIONES BILATERALES: DEFINICIÓN Y CONTENIDOS}

El proceso de reacomodamiento y búsqueda de complementariedad antes mencionado afectó a los dos paises, pero con motivaciones y contenido diferentes. Proceso iniciado, como veremos, cuando aún no se habían apagado los ecos de la guerra civil española, no comenzó a llamar la atención en los medios internacionales hasta tres años después de comenzada la contienda mundial, más concretamente en 1942, por lo que creo pertinente tomar ese año como punto de partida del análisis.

Durante el mencionado período se produjo una suerte de divisoria de aguas en la situación internacional tanto de Argentina como de España. Desde la perspectiva española, en el transcurso de 1942 tuvo lugar el desplazamiento desde una posición abiertamente pro-Eje, favorecida principalmente por las tendencias falangistas dentro del gobierno y amparada por el propio Franco, hacia las propuestas de otros grupos principalmente sectores del ejército- para quienes el interés de España residía en una política de mayor "neutralidad" en el sentido estricto del término. 
Uno de los aspectos de ese cambio de estrategia interesa particularmente al tema que estamos tratando: la idea acariciada por el ministro Jordana de formar un "bloque ibérico " ${ }^{2}$ que incluyese a España, Portugal, Chile y la Argentina, que habria de ampliarse hasta formar un «bloque de neutrales" con la incorporación del Vaticano, Suiza y Suecia.

Ahora bien, de las dos naciones hispanoamericanas antes mencionadas, Argentina era la que llevaba una política neutral más decidida; de hecho, muy poco tiempo después Chile rompería relaciones con el Eje. Por añadidura, el gobierno de Buenos Aires se hallaba abocado en esos momentos, como veremos, a una acción iberoamericana muy compatible con los designios del nuevo ministro español. Finalmente, el gobierno argentino habia mostrado interés por las ideas discutidas en España a comienzos de 1942, sobre la posibilidad de formar el Bloque Ibérico antes mencionado, que como intermediario contribuyese al pronto final de la guerra. No extraña, pues, que dentro de la politica hacia Hispanoamérica emprendida por Jordana en esta nueva etapa al frente de Asuntos Exteriores, fuese Argentina la receptora de sus mayores esfuerzos, buscando en ella un punto de apoyo para su objetivo de legitimación de una postura internacional lastrada por los espúreos vínculos con la Alemania de Hitler desde la guerra civil. En efecto, la Argentina reunía un conjunto de condiciones que podían hacer muy beneficioso un estrechamiento de vínculos: era un país hispanoamericano, y como tal ayudaba a afianzar una identificación alternativa al Eje; era neutral, lo que brindaba la oportunidad de un frente común desde el que reafirmar ante el mundo la neutralidad española; sus clases dirigentes eran manifiestamente anticomunistas, y España se disponía a levantar la bandera del anticomunismo como privote de su acción externa; finalmente, era una nación católica, y el catolicismo, como fundamentación de su política de Estado, ofrecía al régimen español una elegante vía de salida por donde conducir su alejamiento del Eje; perspectiva, por lo demás, favorecida por las grandes potencias.

De más está decir que las acciones hacia la Argentina hubieran estado condenadas al fracaso, de no haber encontrado el gobierno peninsular un interlocutor dispuesto a secundarla. Pero la propuesta fue favorecida por el hecho de que el pais del Plata estaba entrando, a su vez, en un momento de crecientes tensiones internacionales. Dos años antes, en 1940, el entonces presidente argentino Roberto Ortiz había advertido a su flamante

Como es bien sabido, la idea había aflorado ya durante el ministerio de su antecesor, Serrano Suñer. 
embajador en Madrid sobre la necesidad de extremar la cautela en las relaciones con España, debido a "delicada situación internacional» en que se hallaba ésta; advertencia que fue hecha desde la cómoda posición de quien no se ha apartado del camino señalado por la mayoria. Pero a partir de 1942, no sólo la península se encontraba en una "posición delicadas; la Argentina, a su vez, había iniciado un espinoso camino que la conduciria a enfrentar las más difíciles circunstancias de su historia en lo que se refiere a las relaciones con el entorno mundial.

Al comenzar la guerra, la Argentina se había unido a las restantes naciones del continente americano para declarar la neutralidad. Se trataba de "una neutralidad legalista, pero no diferente de la de las restantes repúblicas" 3: el gobierno argentino insistía en enmarcar su política en una larga tradición nacional en materia de política exterior, reafirmando la independencia de su acción externa "a cualquier coste», según palabras del entonces canciller argentino, José María Cantilo, al embajador estadounidense en Buenos Aires ${ }^{4}$. En esos momentos iniciales de la contienda, lo que preocupaba a las autoridades argentinas - como a otros gobiernos de América del Sur- era la disyuntiva entre una Europa autárquica, dominada por los nazis, y una América dominada por los Estados Unidos -o, como dijera el mismo ministro Cantilo, entre la "solidaridad continental» y la "libertad de acción»- y a ello se debió el anuncio de que la Argentina no intervendría en pactos militares hemisféricos. Sin embargo, los más conspicuos miembros del gobierno argentino hacian profesión pública de proclividad hacia la causa de las democracias.

Los problemas comenzaron con el ataque japonés a Pearl Harbour, en diciembre de ese año, y la subsiguiente entrada de los Estados Unidos en la guerra. Como es bien sabido, en un corto lapso casi todos los países americanos cortaron relaciones con el Eje o declararon las hostilidades. A partir de ese momento la neutralidad argentina, hasta entonces legitimada por su contextualización en la política continental, se convirtió desde la perspectiva de esa misma política en una posición no legítima.

Hito fundamental en la paulatina ilegitimación de la postura argentina ante la segunda guerra mundial fue la celebración de la Tercera Conferencia Consultiva de Ministros de Relaciones Exteriores, que tuvo lugar en la ciudad de Río de Janeiro en enero de 1942. Dicho evento tenía por objeto discutir la acción que habrían de tomar las repúblicas del

Humphreys, ob. cit., vol. 1, p. 148.

Citado en Escudé, ob. cit., p. 55. 
continente frente al ataque japonés a Pearl Harbour. El país agredido, Estados Unidos, esperaba un rompimiento en bloque de las relaciones con el Eje, sobre la base de los acuerdos panamericanos que establecian reacciones conjuntas en caso de un ataque a cualquier punto del continente.

Pero las tendencias favorables al mantenimiento de la neutralidad estaban ya consolidadas en las altas instancias del gobierno argentino, que desde la muerte del presidente Ortiz estaba encabezado por su antiguo vicepresidente, Ramón Castillo. A la propuesta norteamericana de ruptura con el eje respondió el nuevo ministro de Relaciones Exteriores, Enrique Ruiz Guiñazú, que el hecho de que la bandera norteamericana ondease sobre esas tierras del Pacífico no era suficiente para convertirlas en territorio americano. La negativa de Brasil, Chile y Uruguay a asumir una postura de abierto antagonismo con la Argentina permitió a este último país imponer su opinión en la declaración final, que hubo de limitarse a una "recomendación" de ruptura, sin carácter de obligatoriedad. Fue el último triunfo diplomático argentino en los foros panamericanos, que dividió al Departamento de Estado en dos tendencias que se manifestarian durante toda la guerra en la política de ese organismo frente a la Argentina: una de ellas partidaria de una táctica de extrema dureza, y una segunda más contemporizadora ${ }^{5}$.

A partir de ese momento se pusieron en marcha todos los resortes de la propaganda psicológica e ideológica destinada a identificar a la Argentina como una quinta columna del Eje en el hemisferio occidental ${ }^{6}$. Progresivas presiones de carácter diplomático y económico completaron el mecanismo, orientado a aislar a ese pais del contexto continental y obligarle a abandonar la neutralidad, lo que provocó a su vez la configuración de una política reactiva por parte argentina para lograr la quiebra de ese aislamiento.

Una de las respuestas a las que acudió el gobierno del Plata para combatir el aislamiento fue la de incrementar la acción diplomática hacia los

Sobre la existencia en el seno del gobierno estadounidense de dos políticas hacia la Argentina, paralelas y enfrentadas, cfr. Escude, ob. cit.; Rapoport, ob. cit.; Humphreys, ob. cit; J. Tulchin La Argentina y los Estados Unidos. Historia de una desconfianza, Buenos Aires, 1990. Sobre la actitud argentina frente a la guerra con anterioridad a Pearl Harbor, véase J. Tulchin: "The Argentine proposal for non-belligerency, april 1940", Joumal of Inter-American Studies and World Affairs, vol. 11, 1969, pp. 571-604

- Sobre la politica norteamericana hacia la Argentina en la Segunda Guerra Mundial, además de las obras citadas en la nota anterior puede consultar de Di Tella y Watt, ob. cit.; M. Francis: The Limits of Hegemony. US Relations with Argentina and Chile during World War II, Indiana, 1979; F. Gary: Struggle for hegemony: Argentina, Brazil and the US during World War Second, Miami, 1979. 
paises vecinos, complementando así una política comercial que le estaba dando excelentes resultados desde el comienzo de la guerra; política que tenia, como finalidad inmediata, el incremento de los intercambios interiberoamericanos y, como objetivo último, la construcción de una Zollverein de la región ${ }^{7}$. Desde ese momento, las referencias a la unidad y solidaridad de los países de América del Sur y los llamados a formar un bloque subcontinental se volvieron una constante en las declaraciones públicas de la Cancillería. $Y$, aunque las repetidas apelaciones del gobierno argentino a una acción unitaria de los países iberoamericanos no prendieran en otro terreno que el de la retórica, lo cierto es que la potenciación de relaciones con los paises limitrofes y latinoamericanos en general no dejó de rendir frutos, tanto comerciales como políticos ${ }^{8}$. De hecho, a pesar de ciertos deterioros manifiestos como el que afectó a las relaciones con el Uruguay, o la mutua desconfianza y rivalidad con el Brasil, el aislamiento distó de ser total; las iniciativas norteamericanas hacia la Argentina se estrellaron muchas veces contra la ausencia de colaboración e incluso el resentimiento de las restantes naciones del continente.

Es en esta práctica de reacomodamiento, de redefinición de alianzas internacionales y búsqueda de apoyos externos que se inscriben los aspectos políticos de la potenciación de relaciones con España por parte del gobierno argentino, a partir de su nueva situación de ilegitimidad internacional. De tal forma, la necesidad de España de contar con un interlocutor que levantara la bandera de la neutralidad salió al encuentro de idéntico requerimiento por parte argentina. $Y$ si en la política y la retórica argentinas el doble elemento de catolicismo y anticomunismo no desempeñó el papel central que es señalable en el caso español, los dos gobiernos compartían en cambio la intencionalidad de convertir a los paises hispanoamericanos en destinatarios privilegiados de su ansiado reacomodamiento internacional. Finalmente, si Argentina podia convertirse para España en un pivote de su política hispanoamericana, la primera necesitaba a su vez de un punto de apoyo europeo para su acción internacional. Inalcanzable entonces el socio tradicional, Gran Bretaña, por sus propios compromisos como país beligerante, y limitada la capacidad de elección argentina por la ilegitimación de su postura internacional, España aparecía como un aliado posible y, por añadidura, muy bien dispuesto.

M. Quijada, ob. cit., 2 ${ }^{a}$ Parte. Esta estrategia seria continuada en la posguerra por los dos sucesivos gobiernos peronistas, entre 1946 y 1955; cfr. Idem: "Zollverein e integración sudamericana en la política exterior peronista, 1946-1955. Análisis de un caso de nacionalismo hispanoamericanista", Jahrbuch für Geschichte von Staat, Wirstschaft un Gesellschaft Lateinamerikas. 1993, pp. 371-408.

${ }_{8}$ M. Quijada: Las relaciones hispano-argentinas..., ob. cit., Sección $2^{\mathrm{a}}$. 
Hay una última cuestión que, si bien conviene no magnificarla para evitar caer en fáciles simplificaciones, no puede sin embargo desconocerse: aunque entre los miembros del ejecutivo argentino había una gran heterogeneidad de posturas con respecto al régimen español, y lo mismo puede decirse de las cámaras del parlamento y de la élite que apoyaba al gobierno, el propio presidente Castillo y sobre todo su ministro de Relaciones Exteriores, Ruiz Guinazú, eran simpatizantes y admiradores de la "cruzada" del general Franco. De la misma manera, algunos de los militares que se hicieron cargo del gobierno argentino después del golpe de estado de 1943 habían sido entusiastas partidarios del levantamiento de 1936 y, sobre todo, tomaron muy en cuenta la guerra civil española como un modelo que, si bien negativo, no dejaba de ser un modelo muy presente: para esos militares la guerra española era el ejemplo que debía evitarse a toda costa, ya fuera por la instrumentación de medidas eficaces de orden público, ya por una política obrera que borrara las tensiones surgidas de las desigualdades sociales extremas, como sería el caso proverbial del futuro presidente Perón. Esa fuente de inspiración que las circunstancias españolas de 1936 representaban para algunos de los militares que tomaron el poder en 1943, conllevaba íntimas simpatías para con el régimen que habia puesto fin en la península a lo que ellos veian como una situación de anarquía intolerable. Tales tendencias y simpatías impregnaron de retórica hispanista e hispanófila las relaciones hispano-argentinas de la época, aunque esa coincidencia estuvo lejos de reflejar la identidad ideológica que muchas veces se le ha atribuido, como ha demostrado fehacientemente Marisa González de Oleaga ${ }^{9}$.

Por qué la Argentina, en un momento en que lo que menos podía interesarle era reforzar la imagen internacional de proclividad al Eje, buscó apoyarse en un gobierno lastrado por esa identificación desde su propio nacimiento, es algo que sólo puede explicarse buceando retrospectivamente en los elementos que dieron origen al acercamiento inicial. Para ello es conveniente seguir tomando como punto de partida el año de 1942, que coincidió con la puesta de largo de las relaciones hispano-argentinas. Durante su transcurso ambos países firmaron el mayor acuerdo comercial de su historia mutua hasta ese momento, acompañado de un convenio cultural y de un acuerdo secreto que, silenciado entonces ante la opinión pública, sería utilizado más tarde como uno de los pivotes principales de la

M. González de Oleaga: Las relaciones hispano-argentinas 1939-1946. Identidas, ideologia y crisis, Madrid, 1991; Idem: («ldentidad e ideologia en las relaciones hispano-argentinas (19391946), en A. Iturrieta et al., El Pensamiento politico argentino contemporáneo, Buenos Aires, 1994 
acusación contenida en la denominación antes mencionada de Eje Madrid Buenos-Aires ${ }^{10}$.

Los acuerdos fueron suscritos con gran alharaca publicitaria, y las declaraciones públicas de ambos gobiernos hicieron votos por el porvenir de unas relaciones que se esperaba fueran la base de futuros contactos, de proyección no sólo bilateral sino hispanoamericana. Esos convenios reflejan la búsqueda de complementariedad de los dos países desde distintas perspectivas. A la vez $-y$ esto es lo más importante - simbolizan la distinta envergadura e importancia de cada uno de los componentes de esa complementariedad.

Una parte de los convenios es de carácter cultural. Ambos gobiernos se comprometían a prestar "su apoyo a cuantas iniciativas tiendan a incrementar y robustecer sus relaciones culturales sobre la base de la comunidad de su origen histórico y de su común patrimonio de valores espirituales» "11. El propósito del acuerdo era garantizar una serie de intercambios en el ámbito de la ciencia, las artes, la filmografía y la edición de libros. Tanto la retórica como el contenido de esta parte de los convenios reflejan el intento de conferir a las relaciones bilaterales una base esencialista fundada en la tradición común. Esta esencialización de las relaciones era la misma que ambos gobiernos esgrimian en sus respectivas estrategias hacia los paises hispanoamericanos.

Habia también un anexo confidencial, referido al aprovisionamiento potencial por parte de España de "suministros especiales" destinados a la defensa de la República Argentina, y cuya negociación se realizaria en conversaciones "complementarias y posteriores", por intermedio de una Comisión de Compras que el gobierno argentino destacaria a Madrid ${ }^{12}$. Esta parte secreta de los acuerdos había sido negociada en Buenos Aires por Eduardo Aunós, jefe de la misión española enviada a esa ciudad para discutir y redactar los convenios de 1942. Las limitaciones de tiempo y espacio nos impiden adentrarnos en los detalles, un tanto rocambolescos, de este episodio de las relaciones hispano-argentinas ${ }^{13}$. Interesa en

10 Para un tratamiento detallado de los convenios de 1942, véase M. Quijada, Las relaciones hispano-argentinas..., ob. cit., cap. 10.

11 AMAE, leg. R. 4.955 exp. 2. Para la significación de este acuerdo de 1942 dentro de la politica cultural para Iberoamérica elaborada por el gobierno franquista, cfr. L. Delgado Gómez-Escalonilla: Diplomacia franquista y política cultural hacia Iberoamérica, 1939-1953, Madrid, 1988; Idem: Imperio de Papel. Acción cultural y poilitica exterior durante el primer franquismo. Madrid, 1992.

12 AMAE, leg. R. 2067 exp. 3 y R. 1.767 exp. 63

13 Para un tratamiento in extenso, véase $\mathrm{M}$. Quijada, Las relaciones hispano-argentinas..., cap. 12. 
cambio señalar las dos circunstancias fundamentales que hicieron posible el anexo confidencial: 1) su formulación original como expresión desesperada de uno de los problemas que el gobierno y las fuerzas armadas de la Argentina estimaban como más acuciantes, y que era fruto de su situación de ilegitimación internacional. Ese problema era la negativa de los Estados Unidos a suministrar armas y equipos bélicos, lo que estaba incrementando de forma dramática la brecha tecnológica y armamentística argentina respecto de los países vecinos - particularmente el Brasil-, con la consiguiente alteración del equilibrio geopolítico regional. 2) El hecho de que la aceptación española al requerimiento argentino se debiera a la necesidad acuciante de arbitrar medios de pago para saldar la ingente deuda comercial con ese país, que venía acumulándose desde $1939^{14}$. Deuda cuyo incremento acelerado era posible prever por el contenido sustancial de los propios acuerdos de 1942, abrumadoramente centrados en el intercambio de cereales argentinos por hierro español.

Esto nos lleva al punto fundamental de las relaciones hispano-argentinas, porque la envergadura que asume esa particular propuesta de intercambios comerciales con respecto a los otros dos aspectos antes citados de los acuerdos - cultural y de suministro de material bélico-, es expresión y símbolo a la vez de la circunstancia fundamental que apuntaló el acercamiento hispano-argentino durante el quinquenio de la guerra: el propósito de un incremento y reencauzamiento del comercio bilateral fundado en una supuesta complementariedad económica. Es más que probable que $\sin$ el aspecto económico de las relaciones bilaterales, las connotaciones políticas de las mismas hubieran sido considerablemente disminuidas, si no inexistentes.

Los intercambios comerciales entre países no son necesariamente apolíticos, ni desprovistos de connotaciones ideológicas. Pero tampoco es imprescindible la presencia de ese componente extraeconómico. Este último fue el caso, precisamente, del proceso de incremento y redefinición de los intercambios hispano-argentinos que se produjo a partir de 1939. Ese proceso se inició en realidad a finales de 1939, bajo la primera titularidad de Jordana en Exteriores, como respuesta a la necesidad de abastecer de cereales a los territorios que pasaron a la autoridad franquista en los últimos tramos de la guerra civil. Y continuó a lo largo de los

14 De hecho, el desplazamiento de las negociaciones efectivas sobre el material pedido a una fecha posterior no especificada, demuestra que la parte española tenía pocas dudas sobre las dificultades de realización de esta parte del convenio. Sobre la actuación de Aunós y los más que insatisfactorios resultados de sus negociaciones iniciales, véase ibidem. 
tres años subsiguientes, retroalimentado por la conflictiva situación del sector agricola español y la necesidad argentina de encontrar nuevas fuentes de suministro de insumos básicos para su industria, debido a las distorsiones que venian produciéndose en su sector externo durante la década de los años treinta, y que fueron considerablemente acentuadas por la guerra mundial. Ambas circunstancias contribuyeron a la percepción de un futuro promisorio de complementariedad económica basado en el intercambio de cereales y otras materias primas alimenticias por parte argentina, y de insumos industriales - particularmente hierro- por parte española.

Es conveniente recordar aquí que no fue durante el gobierno nacionalista de Castillo, sino en la prodemocrática gestión del presidente Ortiz - orientada a la liberalización y redemocratización de la vida pública argentina, incluida una campaña de represión contra la propaganda nazi en particular y las ideologías totalitarias en general-, cuando tuvo lugar esa redefinición, tanto de los contenidos como del volumen de los intercambios hispano-argentinos.

En efecto, a pesar de la retórica esencialista que recubrió los acuerdos de 1942, la motivación original -y sustancial- de los mismos, de orden fundamentalmente económico, se debió a una iniciativa del mencionado mandatario, quien en 1940 destacó a un nuevo embajador a Madrid. El diplomático tenía la misión principal de iniciar unas negociaciones que, se esperaba, habían de concluir en un acuerdo comercial beneficioso para los dos países, centrado, como he dicho, en el intercambio de cereales por hierro ${ }^{15}$. Ningún objetivo de política internacional sustentaba la intencionalidad inicial, lo que se refleja en las instrucciones dadas por el presidente Ortiz al flamante embajador -antes mencionadas - sobre la necesidad de llevar dichas negociaciones con extrema cautela y confidencialidad, debido a la “delicada situación» de España en el contexto mundial.

Ortiz guardaba el afecto a España generalizado entre los descendientes de inmigrantes, pero estaba lejos de ser un hispanófilo desde el punto de vista ideológico. Tampoco lo era su canciller, José Maria Cantilo, y la

\footnotetext{
15 Conviene recordar que los intercambios tradicionales entre Argentina y España, con una balanza comercial notablemente favorable a esta ultima, se habían basado sobre todo en el envio de alimentos manufacturados y "delicatessen" de la peninsula al Plata. Con anterioridad a la crisis de los años treinta, Argentina era el primer comprador hispanoamericano de productos españoles y el tercero entre sus clientes internacionales, mientras que a la inversa España ocupaba sólo el décimo segundo lugar entre los compradores de productos argentinos.
} 
intención de potenciar las relaciones con la península obedecía más, como he dicho, a razones de intereses inmediatos argentinos que a simpatías hacia el régimen de Franco. Sin embargo, el propósito de facilitar unos vínculos lo más cordiales posibles con el nuevo régimen se puso de manifiesto en la elección del primer embajador ante el gobierno español surgido de la guerra civil.

El nuevo representante de Argentina en Madrid, Adrián Escobar, no sólo era un reconocido simpatizante franquista, sino que durante la contienda peninsular se había desempeñado como Director General de Correos y Telégrafos de Buenos Aires, organismo que había llevado su identificación y solidaridad con el bando rebelde, al punto de obstaculizar en la medida de lo posible la actuación del sector prorrepublicano en la Argentina ${ }^{16}$. Escobar era, además, conocido por su afinidad con un sector del nacionalismo argentino que se fortaleció con la guerra civil española y desarrolló su acción principal durante los primeros años de la guerra mundial; nucleado en torno a la revista Sol y Luna, surgida precisamente a finales de 1938 al calor de los ecos de la contienda peninsular, este grupo de nacionalistas se había identificado plenamente con los postulados de la Hispanidad.

La presencia de Escobar a la cabeza de la delegación argentina en Madrid, y la posterior titularidad de Ruiz Guiñazú en la cartera de Exteriores, no sólo facilitaron la continuidad de las negociaciones después de la muerte de Ortiz, sino la modificación de la retórica, aspecto de gran importancia por sus efectos potenciales. Con posterioridad a Pearl Harbour, el mantenimiento a ultranza de la neutralidad por parte de Argentina y la ilegitimación creciente de esta póstura en el contexto continental, por un lado, y la redefinición de la neutralidad española introducida por Jordana en su segunda gestión al frente de Exteriores, por otro, favorecieron la profundización de las relaciones bilaterales, que se proyectaron sobre otros ámbitos y objetivos. Se introdujo así el elemento político, motivado por una ilegitimación internacional que ambos países procuraron subsanar, buscando reforzar sus posiciones respectivas mediante una sumatoria de fuerzas.

No obstante lo anterior, las relaciones bilaterales siguieron respondiendo principalmente a los intereses de carácter económico que habían animado la iniciativa de Ortiz. De hecho, frente a la renovación periódica

16 Cfr. M. Quijada: Aires de República, aires de Cruzada. La guerra civil española en la Argentina, Barcelona, 1992 
de los acuerdos comerciales ${ }^{17}$, el aspecto político de las relaciones estuvo sujeto a vacilaciones, marchas y contramarchas. El fracaso de los intentos de legitimación internacional de España llevados a cabo por Jordana, y la complejización creciente de la situación argentina con posterioridad al golpe de estado de junio de 1943, produjeron en las relaciones bilaterales un fenómeno ambivalente de atracción-aprensión. Atracción, porque en el entorno hostil ambos países, huérfanos de apoyos más contundentes, se necesitaban mutuamente. Aprensión, porque cada movimiento conjunto, lejos del efecto de reforzamiento inicialmente buscado, acentuaba y profundizaba el anatema internacional, consolidando la condición de no legitimidad de las respectivas posiciones internacionales.

\section{LAS RELACIONES BILATERALES: LIMITES}

En ese contexto, el gobierno español fue más coherente en la expresión pública de su proclividad hacia la Argentina. En Madrid se seguian los avatares de la política exterior de ese país con extremo interés, y la documentación hispana muestra que su delegado en Washington informaba asidua y puntualmente, sobre todos los movimientos que se producian en esa capital con respecto a Buenos Aires. Cierto es que la delicada situación española le impidió mantenerse siempre a la altura de las expectativas argentinas, tal como ocurriera con la negativa a reconocer al gobierno boliviano nacido del golpe de estado de enero de 1944, que en los medios aliados era considerado producto de las acciones encubiertas de los servicios secretos argentinos. Asimismo, por presiones británicas y norteamericanas rechazó hacerse cargo de los intereses de Japón en Buenos Aires tras la ruptura de relaciones del gobierno argentino con el Eje, en enero de 1944 -iniciativa ésta que, por lo demás, fue recibida en Madrid con escasa complacencia-.

Pero en términos generales, el gobierno español fue para su homólogo del Plata un apoyo importante en los momentos más delicados de su situación internacional. Esto último se puso particularmente de manifiesto en febrero de 1944, cuando se endurecieron las presiones norteamericanas para impedir el reconocimiento del gobierno argentino, tras un cambio en la cabeza del ejecutivo de ese país. En esa ocasión, sólo algunos gobiernos hispanoamericanos y el de Madrid se mantuvieron firmes en el

17 Hubo convenios comerciales en 1939, 1940, 1941 y dos en 1944, además del ya citado de 1942. 
propósito de impedir el aislamiento total del país del Plata; favor que Perón (convertido ya en el hombre fuerte del régimen, al frente de tres carteras ministeriales), no olvidaria y habría de devolver con creces en 1946.

En Buenos Aires, la política con respecto a España fue menos coherente. El gobierno de Franco contaba allí con aliados importantes, como el Subsecretario de Relaciones Exteriores, Oscar Ibarra García, o el propio Perón. Pero esa proclividad hacia la Madre Patria estaba lejos de ser monolítica en el seno de un gobierno heterogéneo, donde el propio mantenimiento de la neutralidad era objeto de enconadas disensiones internas. Más aún, el hecho de simpatizar con el régimen español no era automáticamente sinónimo de apoyo a una política de abierto acercamiento a España. Finalmente, un sector amplio e influyente de la oligarquía argentina, así como la mayoria de las clases medias y el movimiento obrero organizado eran abiertamente proaliados, y su decantación también mayoritaria por el bando republicano durante la guerra civil española ${ }^{18}$ establecía una continuidad entre aquel periodo y el rechazo actual al gobierno de Franco.

Por tales razones, los sucesivos gobiernos militares argentinos entre 1943 y el final de la guerra mundial tendieron a mostrarse vacilantes y temerosos en su política hacia Madrid, lo que se refleja en las múltiples quejas del ministerio español de Asuntos Exteriores ante las reticencias puestas de manifiesto por la diplomacia argentina, ya fuera desplazando la posibilidad de tomar iniciativas internacionales conjuntas a momentos «más propicios» en un futuro nebuloso, ya dejando pasar las oportunidades de defender la postura española en los foros internacionales. Hacia el final de la guerra, se multiplicaron las protestas por la escasa energía puesta de manifiesto por el gobierno militar a la hora de evitar las expresiones antifranquistas en los medios de comunicación argentinos, en las marchas multitudinarias de apoyo a los aliados, o en los actos obreros de boicot al comercio con España. A las quejas españolas solian responder los argentinos con protestas de simpatía hacia la Madre Patria y nebulosas explicaciones sobre las dificultades de impedir las expresiones contrarias al régimen español. Respuestas que dificilmente podían contentar al gobierno de Franco, ansioso por una política pública más decidida. E incapaz de comprender, por lo demás, las diferencias entre el tipo de autoritarismo ejercido por su propio régimen y los condicionamientos a que estaba sujeta una camarilla militar internamente dividida, que no

18 M. Quijada: Aires de Repuiblica, aires de Cruzada..., ob. cit., passim. 
podía - ni lo deseaban tampoco muchos de sus miembros- hacer del aherrojamiento de la opinión pública un medio fundamental de gobierno.

Las distancias existentes en la actuación internacional de cada uno de los dos países hacia el otro eran, en realidad, coherentes con la posición que cada uno de ellos ocupaba en el concierto mundial escindido por la guerra. El régimen español, por su mácula de nacimiento, tenía menos que perder, y también menos que ofrecer. La Argentina, por el contrario, se hallaba en una situación más ambivalente. Su condición de país hispanoamericano le permitía contar con que la desconfianza y el resentimiento que la política de Washington despertaba en varios gobiernos de la región se tradujese en acciones concretas de apoyo por parte de estos últimos, como ocurrió en diversas oportunidades. Asimismo, cuando llegó el momento propicio, tuvo a su favor el respaldo condicionado del sector del Departamento de Estado que siempre se había opuesto a la política de dureza definida por Sumner Welles en 1942. Hacia el final de la guerra, la rehabilitación argentina y su entrada como miembro de pleno derecho en el seno de las flamantes Naciones Unidas, en contraposición a la consolidación del aislamiento internacional de España, reflejan esas diferencias respectivas.

La imposibilidad de extraer beneficios políticos de su acercamiento mutuo - objetivo de las respectivas estrategias de reacomodamiento y redefinición de alianzas afianzadas en 1942 - se fue haciendo más evidente con el transcurso de la guerra. Por el contrario, consecuencia de ese acercamiento fue la acentuación progresiva de la ilegitimación internacional, con el reforzamiento del anatema de haberse erigido ambos paises en un Eje Madrid-Buenos Aires, con Berlín como telón de fondo. Símbolo del fracaso de los propósitos iniciales es el hecho de que ambos gobiernos evitaran cuidadosamente hacer una defensa conjunta, cuando el Libro Azul editado por el Departamento de Estado a comienzos de 1946 volvió a unir los nombres de los dos países en una nueva acción deslegitimadora, apoyada en una pretendida evidencia documental. Han debido pasar muchas décadas para que la apertura de los archivos alemanes, británicos y norteamericanos permitiera a la investigación académica constatar $-y$ demostrar - los escasos fundamentos sobre los que se construyeron las acusaciones del Libro Azul ${ }^{19}$.

\footnotetext{
19 Consultation among the American Republics with respect to the Argentine Situation (Libro Azul), Gobernment Printing Office, Washington, 1946; Libro Azul y Blanco, publicado por el Ministerio de Relaciones Exteriores y Culto, Buenos Aires, 1946; Réplica a la publicacion hecha pore el Departamento de Estado de los Estados Unidos de América de documentos relativos a
} 
Como he dicho antes, el único aspecto de las relaciones bilaterales que se mantuvo constante a lo largo de toda la guerra fue el estrictamente comercial. Los convenios se sucedieron, al igual que los intercambios. Pero esa continuidad no alcanza a ocultar el fracaso de la búsqueda inicial de complementariedad económica.

En efecto, entre 1939 y 1945 la Argentina se convirtió en el principal suministrador de trigo a la hambrienta España. Esta última, a su vez, como compradora de productos argentinos se elevó de la posición número 12 que ocupara en 1935, a la sexta en 1942 y cuarta en 1944. Pero la ordenación así expuesta, tal cual es reflejada por las estadísticas ${ }^{20}$ no toma en cuenta una cuestión fundamental: la acumulación de saldos no amortizados, y las dificultades experimentadas por las autoridades peninsulares para crear medios de pago mediante mecanismos de compensación. La complementariedad buscada inicialmente, centrada en la percepción de una España industrializada capaz de proveer a su socia sudamericana de los insumos industriales que permitieran a ésta redefinir su sector externo - al menos parcialmente - reduciendo la dependencia del mercado norteamericano, se estrelló contra una doble limitación. Durante todo el quinquenio el régimen español estuvo escindido entre un sector preocupado por el abastecimiento alimenticio de la población, que presionaba a los responsables de industria para que incrementaran la provisión de los materiales requeridos por la Argentina, y la resistencia de estos últimos a cumplir con una exigencias que ponían en peligro su propia estrategia de industrialización. Esto reducía la posibilidad de enjugar la deuda creciente mediante el equilibrio de la balanza comercial. Pero tampoco podía recurrir España, con sus arcas exhaustas, a compensar dicha deuda mediante la entrega de divisas. En 1945 , al finalizar la guerra mundial, España debia a su socia sudamericana el doble que en 1942; la cantidad adeudada era igual al monto total de las exportaciones argentinas durante ese mismo año al Brasil, pais que ocupaba la posición número tres en la lista de compradores de productos del Plata ${ }^{21}$.

España (Libro Blanco), publicado por el Ministerio de Asuntos Exteriores, Madrid, 1946. Para un tratamiento detallado de este episodio, véase M. Quijada, Las relaciones hispano-argentinas.... cap. 18.

20 Cámara de Comercio de Buenos Aires: Memoria Anual 1935-1945, Buenos Aires, serie consecutiva periódica; Banco Central de la República Argentina: Memorias Anuales 1935-1945, y Anuarios de Comercio Exterior de la República Argentina, Buenos Aires, series consecutivas periódicas. M. Quijada, Las relaciones hispano-argentinas..., ob. cit., caps. 9 a 11.

21 lom. 
La estrategia de complementariedad económica - diseñada inicialmente como una respuesta a la distorsión de las redes internacionales de intercambio y hecha posible por la situación de excepcionalidad planteada por la guerra mundial-, había fracasado. Lo mismo había ocurrido con la intención de sumar fuerzas en el ámbito de la diplomacia internacional, apelando a la solidaridad de los paises neutrales y, sobre todo, de los países de habla hispana. El acercamiento hispano-argentino no sólo no habia quebrado la ilegitimación internacional de sus respectivas posturas frente a la guerra, sino que habia contribuido a reforzarla, alimentando las suspicacias y los resortes propagandísticos que asimilaban las múltiples facetas del acercamiento hispano-argentino a un "efecto de biombo", destinado a encubrir y promover las intenciones de penetración germana en el continente americano y sus redes de espionaje.

\section{EL EJE NADRID-BUENOS AIRES: EXCESOS Y REALIDADES DE UNA PROPAGANDA DE GUERRA}

Ahora bien, ¿qué sustento tenía en la realidad esa acusación de la existencia de un Eje Madrid-Buenos Aires, con Berlín como lado oculto del triángulo? Para contestar a esta pregunta, es necesario primero señalar algunas diferencias en la situación de los dos países.

A pesar de que la propaganda de guerra identificó a ambos en un mismo plano monocolor, equiparando tanto sus estrategias externas y las ideologías que sustentaban sus gobiernos como las respectivas circunstancias geopoliticas, esa igualación está lejos de reflejarse en los datos de la realidad.

Como he dicho ya, en la primera mitad de 1943, la Argentina se habia convertido en el único país de América Latina que se negaba a adoptar una definición política frente a la polarización vigente. Pero en esa decisión el deseo de un triunfo del Eje, o el peso de concepciones cercanas a algunos postulados nacionalistas, son un elemento más -y no el de mayor significación - en el conjunto de motivaciones profundas y complejas que convergieron en el mantenimiento a ultranza de la política de neutralidad. De ninguna manera puede afirmarse que hubiera en la Argentina un equipo gobernante decididamente pro Eje, como el que gravitó sobre la política externa española en el período en que el ministerio de Asuntos Exteriores estuvo ocupado por Serrano Suñer. Por otra parte, los grupos nacionalistas -único sector político en el que puede detectarse una simpatia ideológica clara por el bando de los totalitarismos- eran minoritarios y extraparlamentarios, y estaban lejos de desempeñar el papel que en España le cupo a la Falange. 
$\mathrm{Ni}$ siquiera habia coincidencias de fondo en las respectivas estrategias hispanoamericanas. En todo caso puede hablarse de familiaridad en los medios, pero no de identidad en los fines. Para apreciar esa diferencia nada mejor que recurrir a los festejos del $450^{\circ}$ aniversario del Descubrimiento, el 12 de octubre de 1942, ocasión en que el gobierno argentino, no casualmente, brindó una estratégica apoyatura a la iniciativa de Jordana de un mensaje radiofónico emitido para el mundo de habla hispana. El discurso del ministro español asumió la forma de una respuesta a palabras previas de Ruiz Guiñazú, quien hizo un encendido elogio del "milagro de la conquista» ${ }^{22}$ y completó las alabanzas al pasado con la siguiente exhortación dirigida al presente $y$ al futuro:

“Hay que efectuar una labor de acercamiento y aproximación fundadas en bases sólidas. Ha pasado ya la época del hispanismo verbal. El hispanoamericanismo ha de ser constructivo, afirmado sólidamente en la realidad, una realidad espiritual, histórica, geográfica y económica. Falta tan sólo cultivarlo y lo haremos, no con palabras, sino con obras, como lo son, por ejemplo, los Convenios suscritos entre España y la República Argentina. La comunidad hispánica tiene una palabra importante que decir en este momento duro y dificultoso para el mundo. Los principios que afirmamos están respaldados por sostenida tradición. $Y$ hemos de laborar por la futura grandeza de la Argentina y de las demás naciones de su linaje, llenos de esperanza en el porvenir de España” ${ }^{23}$.

\section{El discurso de Jordana fue igualmente significativo:}

«Esta es la hora en que cada uno de nosotros, pueblos de habla castellana, vuelve sobre si, clavada la mirada en lo íntimo de su propia alma. y trata de sacar a luz las hondas esencias espirituales de su propio ser. En nosotros mismos y no en el exterior, que nos es ajeno, encontraremos las fuerzas espirituales que han de elevar a cada uno de nuestros pueblos al más alto punto de su grandeza y, como ha dicho el doctor Ruiz Guiñazú, cuanto más grandes seamos y más estrechamente nos unamos en estos ideales, que superan por su espiritualidad a ningún otro, más pesaremos conjuntamente en el porvenir del mundo y mayores serán los servicios que podremos ofrecer, en su dia, en holocausto de una paz sólida y estable" ${ }^{24}$.

Lo que se trasluce en ambos discursos es 1) una problemática coincidente, fundada en la necesidad de legitimar la ausencia de una toma de 
posición compatible, en términos generales, con la extrema polarización impuesta por la guerra mundial y en particular con el bando que más condicionamientos imponía a sus respectivos intereses; y 2) la búsqueda convergente de apoyatura en un espacio común -el «mundo hispánico»para articular una tercera alternativa, respaldada en la apelación a un pasado y un destino comunes. Pero habia una diferencia significativa: en tanto que el mensaje argentino iniciaba y cerraba el círculo en el mismo ámbito al cual se dirigía, el español se justificaba mediante el compromiso con el porvenir del mundo", identificado este último con la causa de la paz. Para el ministro argentino, la estrategia hispanoamericanista era un medio y un fin; para Jordana, sólo un medio.

Otro aspecto de difícil equiparación es el de las circunstancias geopolíticas de ambos países. Mientras la situación geográfica de España la convertía en una zona de operaciones estratégica y, por ende, revestía un interés extremo tanto para las potencias aliadas como para el Eje, el alejado emplazamiento de la Argentina disminuia considerablemente su valor estratégico desde el punto de vista militar ${ }^{25}$. De hecho, una de las razones que esgrimiera Ruiz Guiñazú en Río de Janeiro para justificar la posición argentina - la incapacidad aliada para asegurar su defensa en caso de un ataque alemán- ha sido ampliamente confirmada por la documentación: los militares norteamericanos consideraban imposible la defensa del extremo sur del continente, y advertían que «Buenos Aires, más que ninguna otra capital, debía evitar una dura posición anti-Eje» ${ }^{26}$.

Asimismo, la oficina de aprovisionamiento de los Estados Unidos estaba de acuerdo con Gran Bretaña en que los suministros argentinos eran más importantes para la batalla aliada que la ruptura con el Eje ${ }^{27}$. De hecho, desde el punto de vista material la neutralidad argentina mostraba un sesgo marcadamente pro-británico; mientras que el comercio con Alemania se habia reducido a un nivel infimo, las exportaciones al Reino

25 J. Cortada, Two Nations/ over time. Spain and the United States, Westport, 1978; V. Morales Lezcano: Historia de la no beligerancia española durante la $2^{a}$ guerra mundial, Valencia, 1980; K.J. Ruhl: Franco, Falange y el Tercer Reich. España durante la II Guerra Mundial, Madrid, 1986.

26 Escude, ob. cit., p. 96. Según la documentación de los Registros Militares de los National Archives, «después de la destrucción de la flota del Pacífico y dada la necesidad de escoltar convoyes en el Atlántico, la marina norteamericana a duras penas podia proteger el canal. Los estrategas norteamericanos estaban expresamente preocupados por la debilidad argentina y la amenaza que representaba el Estrecho de Magallanes". Ibídem. Véase también J. Child: "From "color" to "rainbow": US Strategic Planning for Latin America, 1919-1945", Journal for InterAmerican Studies and World Affairs. 1979.

Humphreys, ob. cit., vol. 2. pp. 154-155. 
Unido no dejaban de aumentar. Además de depender de la Argentina para el suministro alimenticio de la población civil y las tropas, los británicos habian obtenido de aquel país unas condiciones de pago notoriamente beneficiosas, mediante libras bloqueadas y al $0 \%$ de interés. Esta era otra circunstancia que diferenciaba la posición argentina de la mantenida por España, cuyo suministro a Alemania de elementos esenciales --no sólo alimentos, sino especialmente materiales básicos para su industria de guerra- se convirtió en uno de los aspectos más curiosos de la batalla política, diplomática y comercial llevada a cabo por las potencias aliadas con respecto a España: la compra, muchas veces mediante presiones, de materias primas de importancia bélica como el wolframio y el tungsteno, con el solo objetivo de evitar que fueran vendidas a Alemania ${ }^{28}$.

Estas diferencias esenciales en la situación de uno y otro país se ponen de manifiesto en las metas perseguidas por la política aliada frente a cada uno de ellos. Mientras la táctica aplicada a España tenia por objeto impedir que entrase en la guerra junto al Eje y, por ende, evitar que abandonase la neutralidad, en el caso argentino la finalidad buscada era exactamente la opuesta: obligarla a abandonar la neutralidad mediante una decidida y expresa basculación hacia el bando aliado; expresa, porque no se trataba de impulsar a la Argentina a un apoyo de hecho - que ya existía - sino formal y declarado.

Si hubo una constante que afectara de manera equivalente a ambas naciones, esa constante fue el contraste entre una acción diplomática británica, más hábil y conocedora de la mentalidad con la que tenía que habérselas, y la norteamericana, tendente al juicio sin matices fundado en un conocimiento muy imperfecto de la idiosincrasia y los comportamientos internos de los países en cuestión.

Pero incluso en este mismo tema de la política que las potencias aliadas esgrimieron hacia España y la Argentina, se ponen de manifiesto otras diferencias esenciales. Por un lado, lo que pivotaba en torno al caso español -y no al de las relaciones hispanoargentinas- era la suerte de la guerra, y por esa razón el gobierno norteamericano no vacilaría en flexibilizar su táctica hacia Madrid cuando las necesidades de la contienda así lo aconsejasen; por otro, la pertenencia de España al área de influencia británica era algo que ninguno de los dos gobiernos anglosajones ponía en duda. En el caso argentino, no era el desarrollo del conflicto bélico lo que

28 Ruhl, ob. cit., pp. 39 y ss.; A. Viñas et al. Política comercial exterior de España (19311975), vol. 1, cap. III. 
estaba en cuestión, sino la política de solidaridad continental en el marco de la hegemonía estadounidense y el desplazamiento de Gran Bretaña como referente fundamental de la estructura externa argentina, factor este último del que dependía la posición del país del Plata en el ámbito americano en general y frente a los Estados Unidos en particular. La inflexibilidad fue, por ende, la tónica fundamental que presidió no sólo la política de los Estados Unidos, sino la mayor parte de las actitudes argentinas, en esa guerra diplomática y política en la que lo que menos contaba era la verdadera guerra, que transcurría muy lejos en el espacio.

En esa lucha no cruenta, pero enconada, se entremezclaron las relaciones hispano-argentinas cuyos alcances hemos intentado definir. La coyuntural convergencia basada en la no ruptura de relaciones con el Eje, fue acusada de servir como instrumento de la expansión germana en el cono sur, y de facilitar la acción de sus redes de espionaje, con Falange como centro de estas últimas.

Para definir los alcances y limites de esas acusaciones ${ }^{29}$, es necesario inicialmente tener en cuenta la vinculación existente entre una serie de circunstancias efectivas que, en el contexto de la conflagración mundial, alimentarian la identificación del Eje Madrid-Buenos Aires: 1) la convergencia durante la guerra de algunas operaciones del Reich en el Cono Sur, con la acción de Falange en la misma región; 2) los contactos aparentemente fluidos mantenidos por la embajada de España con las representaciones de los paises del Eje en Buenos Aires, especialmente con la alemana, y 3) el aprovechamiento de los territorios español y argentino para acciones de espionaje y establecimiento de redes de comunicación e información por parte de los países beligerantes. A caballo entre los anteriores factores, aparece la acción concertada de los servicios alemanes con elementos afectos de ambos países, y de todo ello surge también el especial interés que revestía para Alemania la presencia española en la Argentina.

Ese interés fue permanentemente resaltado por la propaganda aliada, vinculándolo, como ya he dicho, a una supuesta estrategia de dominación política y territorial del Tercer Reich sobre el cono sur -y especialmente sobre la Argentina- dentro de la teoría del "espacio vital" que caracterizó a una parte de la geopolítica nacionalsocialista. En tal contexto, tanto la

29 Interesantes muestras del papel asignado a las relaciones hispano-argentinas en la propaganda aliada son los siguientes ulibros de guerran: S. Bradford: The Battle for Buenos Aires, New York, 1943; A. Chase: Falange. The Axis Secret Army in the Americas, New York, $1943 ;$ R. Josephs: Argentine Diary, New York, 1944. 
representación española como la Falange y los elementos nacionalistas locales habrían actuado como meros instrumentos para la consecución de dichos objetivos, según el plan que, supuestamente, habría sido elaborado por el general von Faupel y aprobado por Hitler.

No obstante, se sabe hoy que no hubo tal plan o, si en efecto existió, no formó parte de la estrategia externa del Reich, que con respecto a América del Sur fue de carácter pragmático y centrada principalmente en intereses comerciales. En el caso específico de la Argentina, investigaciones recientes y no tan recientes ${ }^{30}$ han demostrado incluso que no sólo la actuación alemana, sino la acción de los servicios estadounidenses contra la actividad del Reich en el país del Plata, y especialmente contra la colectividad germano-argentina (principal campo de acción de la propaganda nazi), respondía, más que a motivaciones estratégicas, a una ya larga rivalidad económica en la región ${ }^{31}$. Desde esta perspectiva, se desvirtúa el carácter exclusivamente puntual e inmediato de la "guerra de los servicios secretos" en el Cono Sur, para enmarcarse en una problemática compleja que excede los límites estrictos del conflicto bélico y que se superpone al telón de fondo de las competencias y desplazamientos hegemónicos en la región.

Ahora bien, es natural que en el contexto de la guerra, la actividad propagandística de los agentes nazis en la Argentina fuera percibida por sus enemigos como una táctica dirigida a objetivos expansionistas de largo alcance y perfectamente definidos. La visión de un avance militar alemán hacia el sur, culminado en la anexión de territorio latinoamericano a una

3o Cfr. A. Ebel: Die diplomatischen Bezihungen des Drittes Reiches Handelspolitik, Landau Pfalz, 1970; R. Pommerin: Das Dritte Reich und Lateinamerika, Düsseldorf. 1977; W.D. Smith: The Ideological Origins of Nazi imperialism. New York, 1986, y sobre todo los trabajos de R. Newton: "The United States, the German Argentines and the Myth of the Fourth Reich", Hispanic American Historical Review, 1984, vol. 64, pp. 81-100; "The neutralization of Fritz Mendel: Notes on Wartime Journalism, the Arms Trade, and Anglo-American Rivalry in Argentina during World War H". Hispanic American Historical Review, 1986, vol. 63, pp. 541-579, y The "Nazi Menace" in Argentina, 1931-1947. Stanford, 1992

31 Durante los años treinta se estima que las inversiones alemanas en la Argentina se elevaban a alrededor de 400 millones de dólares. A lo largo de la década anterior se fueron estableciendo en ese país cerca de 80 fábricas germanas, concentradas en rubros tales como química, productos farmacéuticos, metalurgia, equipos eléctricos y construcción pesada, todos ellos campos en los que entraban en abierta competencia con las inversiones norteamericanas. Cfr. R. Newton, "The neutralization of Fritz Mandel...", ob. cit. Sobre las ventajas comparativas que presentaba la relación económica de Argentina con Alemania con respecto a los Estados Unidos, véase $R$. Newton: "Disorderly Succession: Great Britain, the United States and the "Nazi Menace" in Argentina, 1938-1947", en G. Di Tella y D.C. Watt: Argentina between the Great Powers 19391946, Oxford, 1989, pp. 122-123. 
Europa reorganizada bajo el Nuevo Orden, era una pesadilla que perseguia al Departamento de Estado norteamericano ${ }^{32}$. Sin embargo, las investigaciones que se vienen realizando desde 1945 en la documentación alemana, lejos de fundamentar esas perspectivas, las contradicen. Como afirma Ronald Newton, «hoy, cuarenta años más tarde, estamos obligados a dar crédito a aquellos funcionarios de la cancillería alemana interrogados inmediatamente después de la guerra, quienes admitieron libremente que buscaban expandir el enclave económico alemán en la Argentina, pero negaron cualquier tipo de objetivos estratégicos de largo alcance" ${ }^{33}$.

¿Cuál era, entonces, el papel que España podía desempeñar en la Argentina, que tanto interés revestía para el gobierno alemán? Ese papel era múltiple. Por un lado, son obvios los beneficios, tanto de carácter político como económico, que reportaría a Alemania un debilitamiento de la posición estadounidense mediante el quiebre de la política panamericana. La prédica hispanoamericanista como una táctica de oposición a aquélla tenía raices profundas en el continente, y la imagen de España podía actuar como elemento nuclearizador de dicha tendencia. Desde esta perspectiva, la percepción norteamericana de España como «la mayor amenaza para la unidad de las naciones americanas ${ }^{34}$, aunque muy exagerada, no dejaba de tener un cierto contenido de veracidad, más por su carga simbólica que por su potencialidad material.

En segundo lugar, la propaganda española, dirigida por sus propios intereses a favorecer el mantenimiento de la neutralidad, coincidía tácticamente con las aspiraciones alemanas, cuyo objetivo principal era que Argentina no se apartara de esa línea de acción. Objetivo que respondia tanto a necesidades propias de la contienda como al mantenimiento de las empresas germanas en el pais del Plata, y a la preservación de la autonomía cultural de la comunidad de inmigrantes de ese origen alli asentados, destinatarios fundamentales de la propaganda nazi ${ }^{35}$.

32 Sobre la utilización por parte del Departamento de Estado de un mapa que mostraba los supuestos planes del Reich para conquistar Sudamérica, y que más tarde se demostró que era espurio, véase W. Kimball: "The Jugglers': Franlankin D. Roosevelt and Anglo-American Competition in Latin America", en G. Di Tella y D.C. Watt: Argentina between de Great Powrs. ob. cit., pp. 23 y ss.

Newton, "The United States, the German Argentines...", ob. cit., p. 89.

Bradtord: The Battle for Buenos Aires, ob. cit., p. 106.

C. Jackisch, en El nazismo y los refugiados alemanes en la Argentina, 1933-1945, Buenos Aires, 1989 , pp. 223 y ss., ha demostrado que la propanga nazi dirigida a la comunidad de alemanes radicados en la Argentina - y la aceptación de éstos como miembros de las organizaciones nacionalsocialistas- se circunscribia, por decisión oficial del gobierno del Reich, a aquellos que no hubieran perdido su nacionalidad de origen ni tuvieran doble ciudadania, haciendo una separación 
Asimismo, la acción directa de la diplomacia y la propaganda alemanas en la Argentina encontraba límites muy definidos. La mayor parte de la población políticamente activa era proaliada y lo mismo ocurria con los principales periódicos y medios de comunicación. Los movimientos de la Embajada germana eran observados con suspicacia y se convertian en fácil presa de acusaciones y denuncias. España, por el contrario, aunque se hallase bajo un gobierno de reconocidas simpatías pro-Eje, tanto por su condición de antigua metrópoli como por el hecho de ser la patria de origen de una numerosa y bien reputada colonia de inmigrantes, tenía una imagen menos comprometida y sus representantes gozaban de una mayor capacidad de acción que sus colegas germanos. Por ello, los alemanes sabian que sus tácticas propagandisticas en favor del mantenimiento de la neutralidad - que encontraban eco fundamentalmente en los grupos nacionalistas- serian más efectivas si eran realizadas a partir de una acción coordinada con los españoles. No extraña, pues, que entre las tácticas nazis figurase el subsidio a la prensa pro-franquista de la comunidad española, tal como ocurría con las publicaciones nacionalistas ${ }^{36}$.

Finalmente, la neutralidad argentina favorecia las operaciones encubiertas del Reich en su territorio, operaciones que podían ser secundadas por elementos españoles afectos que, como ya se ha señalado, gozaban de una libertad de acción que a los germanos estaba vedada. En este sentido, distaba mucho de ser una fantasia la existencia de "triángulos de información" constituidos por los servicios secretos nazis, que utilizaban territorio español como centro de operaciones y cuyo tercer vértice se asentaba en Buenos Aires. Por ejemplo, basado en documentación alemana, K.J. Ruhl ${ }^{37}$ ha reconstruido la organización de un servicio secreto de correos destinado a América del Sur y dirigido en Madrid por Karl

\footnotetext{
tajante además entre los emigrantes nacidos en Alemania, y los descendientes de alemanes nacidos en el exterior. Como señala la autora, esta resolución era una notable condescendencia hacia las buenas relaciones con la Argentina, ya que implicaba desestimar no sólo el principio del ius sanguinis, sino dejar de lado la idea racial de la "comunidad del pueblo ario"; y añade que éstas y otras medidas "muestran claramente que el destinatario de la actividad nazi no era la sociedad argentina»; /d. pp. 228-229

36 Las publicaciones subsidiadas por la embajada alemana tenian un grave fallo en cuanto a su alcance propagandistico: su circulación se limitaba a un sector numéricamente reducido de la población, de filiación nacionalista, puesto que los periódicos de gran tirada eran aliadófilos. La capacidad de proselitismo de tales órganos de prensa era por lo tanto escasa, ya que sus lectores estaban convencidos de antemano. Por otra parte, es significativo de la condición autónoma de este tipo de acciones alemanas, el hecho de que en dichas listas no figure Orientación Española, órgano oficial de Falange en Buenos Aires.
}

37 Ruhl, ob. cit., pp. 55 y ss. 
Arnold, Subjefe de la Bandera de Asalto de las SS ${ }^{38}$. Asimismo, ciudadanos argentinos de ascendencia alemana trabajaban en empresas de capital alemán, establecidas en España, que se utilizaban como tapadera de espionaje para el Reich ${ }^{39}$.

Un importante eje nuclearizador de redes informativas y propagandisticas era Wilhelm von Faupel. Sus contactos con elementos nacionalistas dentro del ejército argentino ${ }^{40}$ y de Falange facilitaron probablemente su participación en estos movimientos triangulares, que el activo general organizaba desde España mediante una eficiente red de comunicación con "camisas viejas" ${ }^{41}$.

Asimismo, la documentación pone de manifiesto el activo papel desempeñado por barcos españoles en el tráfico de hombres e información de carácter pro-Eje entre Europa y la Argentina. En diversas ocasiones, navíos de esa bandera se vieron envueltos en escándalos de espionaje nazi, como el muy sonado caso de Leon («alias» Leopold) Hirsch, agente

38 Arnold, destacado en la capital española como "enviado especial» para los servicios con América Latina, encubría sus actividades mediante un trabajo de media jornada en la "Compañía General de Lanas", filial de Sofindus. Su tarea consistia en recoger el correo regular de Berlín y reenviarlo al delegado del SD en Buenos Aires, Siegfred Becker, utilizando para ello la ayuda de marinos españoles. Para estas actividades se empleaba por lo general a falangistas o veteranos de la División Azul. A través del ciudadano hispano-alemán Jorge Demmel, propietario del bar "Germania" en Bilbao, se recibia también correo de Sudamérica Ibidem.

39 Ibidem

40 Von Faupel se habia desempeñado como instructor del Colegio Militar argentino en 1912. Más tarde, entre 1921 y 1926, fue consejero del Inspector General del ejército, cargo ocupado entonces nada menos que por el general Uriburu, autor del golpe de estado de 1930. Al abandonar la Argentina se trasladó al Perú donde aceptó un ofrecimiento para organizar el ejército de ese país. Años más tarde, desde su puesto de director del Instituto Iberoamericano de Berlin, realizó una intensa labor de propaganda sobre las fuerzas armadas de los paises latinoamericanos donde habia residido. En 1939 publico en castellano el libro titulado Alemania y el Mundo Iberoamericano que circuló profusamente entre los elementos nacionalistas argentinos. En él se hacia el ditirambo del régimen nacional-socialista, se destacaba el "carácter pacifico de las relaciones entre Alemania y América Latina" y se ponia énfasis en la "significación trascendental" de la "derrota comunista en España». Cfr. entre otros C. Buchrucker: Nacionalismo y peronismo. La Argentina en la crisis ideológica mundial, 1927-1955, Buenos Aires, 1987

${ }^{4}$ Ruhl, ob cit. p. 59. Von Faupel se había desempeñado como primer embajador de Alemania ante Franco durante la guerra civil, aunque fue finalmente destituido por inmiscuirse en asuntos de Falange y oponerse al comandante de la Legión Cóndor. Iniciada ya la contienda mundial, regresó a España y desde la sede madrileña del Instituto Cientifico Alemán procuró intervenir en la politica interna española e influir sobre las decisiones del Ministerio de Asuntos Exteriores, basándose para ello en "sus experiencias en América del Sur». Ibidem. Este tipo de actuación, que se conoce hoy gracias a la apertura de los archivos, está muy alejada de las afirmaciones de la propaganda aliada durante la guerra, donde von Faupel aparecía como uno de los artifices del levantamiento franquista de 1936, y se estimaba que tanto el Ministerio de Asuntos Exteriores como buena parte del gobierno español bailaba al son que el activo general tenía a bien marcar. Cfr. A. CHASE: Falange. The Axis Secret Army in the Americas, ob. cit., pp. 178 y ss. 
austríaco al servicio de Hitler, detenido por los servicios británicos a bordo del vapor español Cabo de Hornos en 1941, cuando se dirigía a Buenos Aires ${ }^{42}$. Igualmente, a lo largo de la guerra existió un activo tráfico de propaganda alemana (peliculas, fotografías, folletos, etc.) realizada por tripulantes de una extensa lista de navios españoles ${ }^{43}$. Y fueron recurrentes las denuncias internacionales sobre la utilización de barcos españoles para el traslado clandestino de alemanes. A causa de ello, en marzo de 1941 el Ministerio de Asuntos Exteriores de Madrid hubo de dictar una Orden a sus embajadas y consulados en América Latina con el fin de que mediante estrecha vigilancia se impidiese la entrada de polizones en buques de su bandera ${ }^{44}$.

En resumen, en el contexto enfervorizado del conflicto mundial la afirmación de que las relaciones hispano-argentinas implicaban una acción concertada tendente a "servir de biombo" a las aspiraciones expansionistas de Berlín formó parte de una activa propaganda de guerra, que caló hondo en la opinión pública internacional. No obstante, todo indica que no hubo tal acción concertada, como tampoco existieron estrategias globales de expansión a largo plazo en América del Sur por parte del Tercer Reich.

Sin embargo, también es indiscutible que la politica exterior de ambos países brindó a los servicios alemanes un campo de acción triangular que pudo ser utilizado con provecho para fines de propaganda y espionaje. En el desarrollo de estas operaciones, fue un factor no desdeñable la evidente tolerancia practicada por las autoridades argentinas hacia unas actividades que con toda probabilidad conocian. Asimismo, la expresa inclinación pro-Eje de la España franquista durante los primeros años de la guerra creó una dinámica oficial y extraoficial de apoyo a las actividades alemanas, que se mantuvo hasta casi finalizar la contienda. No parece, sin embargo, que esas acciones de apoyo tuvieran en la Argentina la efectividad y la envergadura que se le atribuyó en la época.

42 Hirsch se dirigia a Buenos Aires en compañia de otros ocho espias nazis llevando consigo, además de la considerable suma de 50.000 dólares, comprometedores documentos que contenían órdenes de Hitler para dirigir actividades de la Gestapo en la Argentina. Puede seguirse este episodio en la prensa bonaerense de octubre-noviembre de 1941

43 Entre ellos figuran los vapores Mar Cantábrico, Júpiter, Monte Maragón, Monte Gurugú. Monte Teide, Santi, El Neptuno y Monte Amboto. AGA-AMAE, Caja 9.247 legs. 37,39 y 45 ; y Caja 9.246 leg. 16.

${ }_{44}$ Para un seguimiento más detallado de estos temas, véase M. Quijada: Las relaciones hispano-argentinas..., ob. cit., pp. 470-491. 
En última instancia, hoy se puede afirmar que las circunstancias hasta aquí reseñadas, que proporcionaron las bases para la construcción de una imagen que caracterizaba a las relaciones hispano-argentinas como un «Eje Madrid-Buenos Aires» al servicio del Reich, demostrarian ser mucho menos perjudiciales para las acciones de guerra de las potencias aliadas, que para los dos paises unidos bajo esa denominación común. 